\title{
molecules
}

ISSN 1420-3049

www.mdpi.com/journal/molecules

Article

\section{Effects of Dietary Brazilian Palm Oil (Mauritia flexuosa L.) on Cholesterol Profile and Vitamin A and E Status of Rats}

\author{
Jailane de Souza Aquino ${ }^{1, *}$, Juliana Késsia Barbosa Soares ${ }^{2}$, Marciane Magnani ${ }^{3}$, \\ Thayza Christina Montenegro Stamford ${ }^{4}$, Robson de Jesus Mascarenhas ${ }^{5}$, \\ Renata Leite Tavares ${ }^{1}$ and Tânia Lúcia Montenegro Stamford ${ }^{6}$
}

1 Departamento de Nutrição/CCS, Universidade Federal da Paraíba, Campus I, s/n. Castelo Branco, 58051-900 João Pessoa-PB, Brasil; E-Mail: renataltav@gmail.com

2 Departamento de Nutrição/CES, Universidade Federal de Campina Grande, Olho d'agua da Bica, s/n, 58175-000 Cuité-PB, Brasil; E-Mail: julianakessia2@gmail.com

3 Departamento de Engenharia de Alimentos, Universidade Federal da Paraíba, Campus I, s/n. Castelo Branco, 58051-970 João Pessoa-PB, Brasil; E-Mail: magnani2@gmail.com

4 Departamento de Medicina Tropical/CCS, Universidade Federal de Pernambuco, Campus Recife, s/n, Cidade Universitária, 50670-901 Recife-PE, Brasil; E-Mail: thayzastamford@yahoo.com.br

5 Instituto Federal de Educação, Ciência e Tecnologia do Sertão Pernambucano, Campus Petrolina, BR 407, km 08, Jd. São Paulo, 56314-520 Petrolina-PE, Brasil; E-Mail: robsonjmjm@gmail.com

6 Departamento de Nutrição/ CCS, Universidade Federal de Pernambuco, Campus Recife, s/n, Cidade Universitária, 50670-901 Recife-PE, Brasil; E-Mail: tlmstamford@yahoo.com.br

* Author to whom correspondence should be addressed; E-Mail: magnani2@gmail.com; Tel.: +55-83-3216-7807.

Academic Editors: Emilie Combet and Maria Rosário Bronze

Received: 25 February 2015 / Accepted: 11 May 2015 / Published: 19 May 2015

\begin{abstract}
In vitro studies have been carried out to establish the nutritional differences between crude and refined vegetable oils; however, the impact of the consumption of these foods on metabolism, in particular the effect of buriti oil, needs to be further evaluated. The aim of this study was to evaluate the biochemical and murine parameters and the vitamin A and $\mathrm{E}$ status in young rats fed with diets supplemented with crude or refined buriti oil. The animals $(\mathrm{n}=30)$ were randomized into three groups receiving diet added of soybean oil (control), crude buriti oil (CBO) and refined buriti oil (RBO) for 28 days. Rats fed with diet added of refined buriti oil (RBO) showed reduced total cholesterol (up to 60.27\%), LDL $(64.75 \%)$, triglycerides $(55.47 \%)$ and enzyme aspartate transaminase $(21.57 \%)$ compared to
\end{abstract}


those fed with diet added of crude oil. Serum and hepatic retinol and tocopherol were higher by two to three times in $\mathrm{CBO}$ and $\mathrm{RBO}$ groups compared to the control group, but no differences were observed for murine parameters. The results indicate that buriti oil is an important source of the antioxidant vitamins $\mathrm{A}$ and $\mathrm{E}$, and refined buriti oil is suggested as alternative to improve the lipid profile of healthy rats.

Keywords: $\alpha$-tocopherol; lipids; refined oil; retinol

\section{Introduction}

The compositions of crude oils obtained from plant species contain many bioactive compounds such as essential fatty acids and antioxidant vitamins. Studies involving diets with added vegetable oils have reported significant beneficial effects on health, particularly on the vitamin status and the lipid-lowering effects on humans, which is directly associated with the modulation of the antioxidant system homeostasis [1] and reduction of adipose tissue and insulin resistance [2,3]. Virgin olive and extra virgin olive oils are the only non-refined oils widely consumed in the crude form worldwide. In the Mediterranean diet, the extra virgin oil is considered an important source of antioxidants and unsaturated fats which are associated with decreased risk of cardiovascular disease, metabolic syndrome, obesity, type-2 diabetes and hypertension [4,5].

With the exception of olive oil, most vegetable oils need to be refined because during the post-harvest handling, undesirable substances such as phospholipids, monoacylglycerols, diacylglycerols, free fatty acids, pigments, flavor components and sulfur compounds can be incorporated into the oils [6]. The oil refining process consists of degumming, neutralization, washing and drying steps, which improve some physicochemical characteristics such as acidity and the percentage of free fatty acids and increases thermal stability [7]. However, this process can result in degradation of sensitive bioactive compounds such as tocopherols [6] and carotenoids [7]. In this context, in vitro studies involving vegetable oils before and after refinement have been carried out to evaluate if processing compromises the functional potential of these oils [8-10].

Many studies have been performed to evaluate the effect of the consumption of vegetable oils on lipid metabolism and vitamins antioxidant status in animal models [11-13]. Although some in vitro studies have been conducted in order to highlight the benefits of the Brazilian palm (buriti) oil related to its lipid composition and quantification of vitamins $\mathrm{A}$ and $\mathrm{E}$ [7,14], there is a gap in knowledge related to the effects of the consumption of buriti oil in the diet on metabolism, particularly before and after the refining process. Buriti palm (Mauritia flexuosa) is a species native to Brazil and considered one of the most important vegetal sources of carotenoids and vitamin A [15]. Buriti oil is usually consumed as a crude oil presenting $3.1 \%$ saturated fatty acids, $92.3 \%$ monounsaturated fatty acids, $4.6 \%$ polyunsaturated fatty acids and considerable amounts of $\beta$-carotene $\left(911.4 \mathrm{mg} \cdot \mathrm{kg}^{-1}\right)$ and tocopherol $\left(800 \mathrm{mg} / \mathrm{kg}^{-1}\right)[7,16]$. In this context, the present study aimed to evaluate the influence of the addition of crude or refined buriti oil in the diets on the biochemical and murine parameters and vitamin A and E status in young rats. 


\section{Results and Discussion}

\subsection{Assessment of Diet Intake, Weight Gain and Feed Efficiency Coefficient (FEC)}

Weight gain and diet intake did not differ between groups $(p>0.05)$ receiving crude or refined buriti oil (Table 1). Similar results were reported by Berger et al. [17] in a study assessing the effects of addition of crude or refined amaranth oil (Amaranthus caudatus L.) in the diet of hamsters.

Table 1. Intake, weight gain and feed efficiency coefficient of Wistar rats fed with diets added of soybean oil or refined or crude buriti oil.

\begin{tabular}{cccc}
\hline \multirow{2}{*}{ Variables } & \multicolumn{3}{c}{ Animal Groups } \\
\cline { 2 - 4 } & CG $(\mathbf{n}=\mathbf{1 0})$ & CBO $(\mathbf{n}=\mathbf{1 0})$ & RBO $(\mathbf{n}=\mathbf{1 0})$ \\
\hline Mass gain $(\mathrm{g})$ & $104.98 \pm 14.53^{\mathrm{a}}$ & $91.37 \pm 13.41^{\mathrm{a}}$ & $110.36 \pm 18.16^{\mathrm{a}}$ \\
Diet intake $(\mathrm{g})$ & $336.9 \pm 36.72^{\mathrm{a}}$ & $344.25 \pm 25.67^{\mathrm{a}}$ & $336.55 \pm 21.04^{\mathrm{a}}$ \\
FEC & $0.30 \pm 0.07^{\mathrm{ab}}$ & $0.26 \pm 0.03^{\mathrm{b}}$ & $0.34 \pm 0.07^{\mathrm{a}}$ \\
\hline
\end{tabular}

Means followed by different letters in the same line indicate a significant difference error probability $p<0.05$, according to the Tukey test. Abbreviations: FEC $=$ feed efficiency coefficient. Groups: $\mathrm{CG}=$ control group with AIN-93G diet; $\mathrm{CBO}=$ experimental group with AIN-93G diet added of crude buriti oil; $\mathrm{RBO}=$ Experimental group with AIN-93G diet added of refined buriti oil.

However, the FEC was higher for group receiving diet with refined buriti oil (RBO) compared to that receiving crude buriti oil (CBO). This difference is probably related to the presence of hydrophilic substances such as glycerol, methanol and water, which are reduced during refinement and affect the nutritional value of oils and may also affect feed conversion [18].

\subsection{Murine Anthropometric Parameters}

No differences were observed in the murine parameters of animals receiving buriti (CBO and RBO) and soybean oils (control group), except for abdominal circumference (AC), which was lower $(p<0.05)$ in the control group compared to the other groups (Table 2).

Table 2. Murine variables of Wistar rats fed with diets added of soybean oil or refined or crude buriti oil.

\begin{tabular}{cccc}
\hline Murine & \multicolumn{3}{c}{ Animal Groups } \\
\cline { 2 - 4 } Antropometric Data & CG (n= 10) & CBO $(\mathbf{n}=\mathbf{1 0})$ & RBO $(\mathbf{n}=\mathbf{1 0})$ \\
\hline TC $(\mathrm{cm})$ & $10.55 \pm 1.23^{\mathrm{a}}$ & $11.14 \pm 0.45^{\mathrm{a}}$ & $10.9 \pm 0.46^{\mathrm{a}}$ \\
$\mathrm{AC}(\mathrm{cm})$ & $10.86 \pm 1.43^{\mathrm{b}}$ & $12.41 \pm 1.07^{\mathrm{a}}$ & $12.25 \pm 0.75^{\mathrm{a}}$ \\
$\mathrm{AC} / \mathrm{TC}$ & $1.03 \pm 0.05^{\mathrm{a}}$ & $1.11 \pm 0.03^{\mathrm{a}}$ & $1.12 \pm 0.05^{\mathrm{a}}$ \\
$\mathrm{BL}(\mathrm{cm})$ & $18.27 \pm 1.42^{\mathrm{a}}$ & $18.09 \pm 1.04^{\mathrm{a}}$ & $18.40 \pm 0.97^{\mathrm{a}}$ \\
BW $(\mathrm{g})$ & $136.16 \pm 31.38^{\mathrm{a}}$ & $146.20 \pm 20.09^{\mathrm{a}}$ & $146.23 \pm 24.05^{\mathrm{a}}$ \\
BMI $\left(\mathrm{g} \cdot \mathrm{cm}^{-2}\right)$ & $0.40 \pm 0.05^{\mathrm{a}}$ & $0.45 \pm 0.04^{\mathrm{a}}$ & $0.43 \pm 0.04^{\mathrm{a}}$ \\
Lee index & $0.28 \pm 0.01^{\mathrm{a}}$ & $0.29 \pm 0.01^{\mathrm{a}}$ & $0.26 \pm 0.09^{\mathrm{a}}$ \\
\hline
\end{tabular}

Means followed by different letters in the same line indicate a significant difference error probability $p<0.05$, according to the Tukey test. Abbreviations: $\mathrm{CT}=$ chest circumference; $\mathrm{AC}=$ abdominal circumference; $\mathrm{BL}=$ body length; $\mathrm{BW}=$ body weight; $\mathrm{BMI}=$ Body mass index. Groups: $\mathrm{CG}=$ control group with AIN-93G diet; $\mathrm{CBO}=$ experimental group with AIN-93G diet added of crude buriti oil; $\mathrm{RBO}=$ Experimental group with AIN-93G diet added of refined buriti oil. 
However, the AC value observed in the control group is consistent with reports of rats fed with standard diet [19]. BMI, considered the most sensitive index to detect obesity and carcass fat [15] ranged from 0.40 to $0.45 \mathrm{~g} \cdot \mathrm{cm}^{-2}$ in the animals studied, those values are within normal parameters $(0.38$ and $0.68 \mathrm{~g} \cdot \mathrm{cm}^{-2}$ ) for animals aged $30-150$ days. The BMI values observed in this study were lower than those reported by Santillan et al. [20] for rats fed diets with added soybean or sunflower oil (0:50 to 0:57).

\section{3. $\beta$-Carotene and Alpha Tocopherol in Diet, Blood and Liver of Rats}

Diet containing crude buriti oil had higher vitamin A content (104,652 IU/kg of diet equivalent to $58.14 \mathrm{mg} \beta$-carotene) compared to diet containing refined buriti oil $(97,524 \mathrm{IU} / \mathrm{kg}$ of diet equivalent to $54.18 \mathrm{mg} \beta$-carotene). The lowest vitamin A concentration was found in diet added of soybean oil (80,028 IU/kg equivalent to $44.46 \mathrm{mg}$ of $\beta$-carotene) (Figure 1). Diets added of crude or refined buriti oil had higher vitamin A content than values observed by Ramos et al. [21] and Siqueira et al. [22] for diets containing whole pulp of acrocomia (Acrocomia aculeata) and cassava (Manihot esculenta crantz), respectively.

A

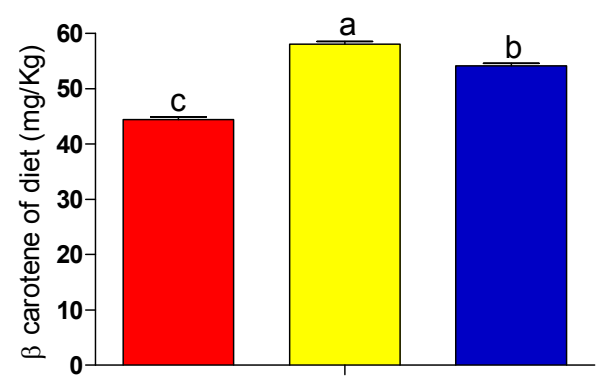

C

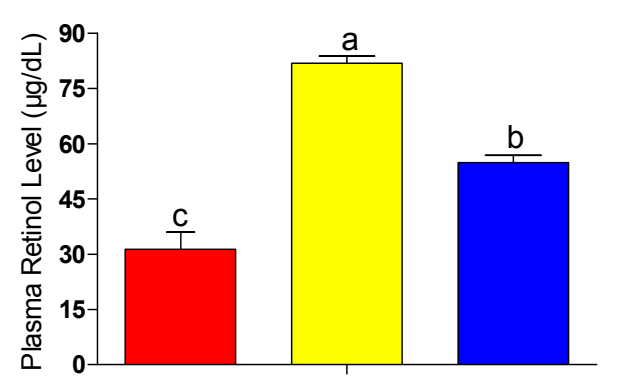

B

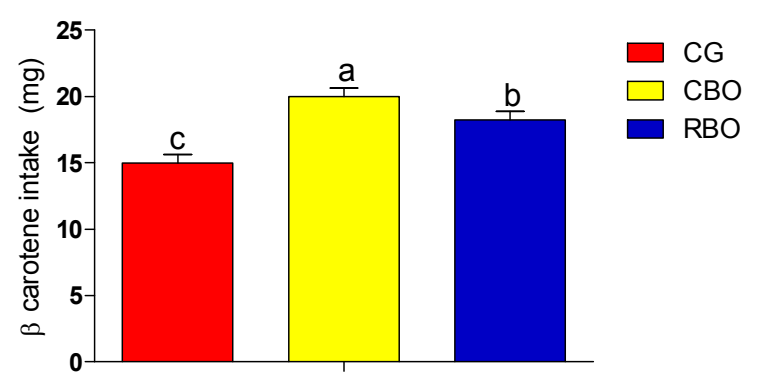

D

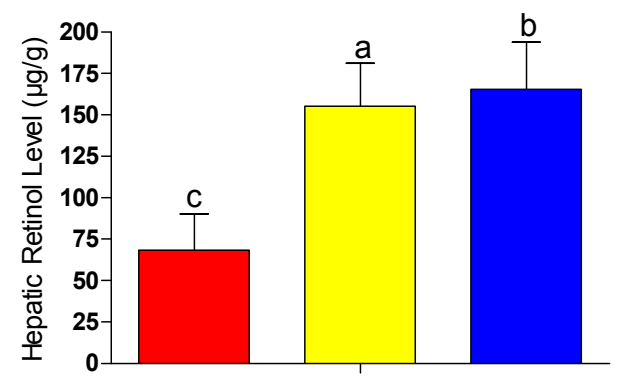

Figure 1. Content and intake of $\beta$-carotene of diet and serum and hepatic retinol of Wistar rats fed with diets added of soybean oil or refined or crude buriti oil. Panel $\mathbf{A}$ : $\beta$-carotene of diet; Panel B: $\beta$-carotene intake; Panel C: Plasma retinol level; Panel D: Hepatic retinol level. Means followed by different letters indicate significant difference with error probability $p<0.05$, according to the Tukey test. Abbreviations: Groups: $\mathrm{CG}=$ control group with AIN-93G diet; $\mathrm{CBO}=$ experimental group with AIN-93G diet with crude buriti oil; $\mathrm{RBO}=$ Experimental group with AIN-93G diet with refined buriti oil. 
FAO/WHO [23] and the Institute of Medicine [24] recommend that the daily uptake of retinol equivalent (RE) in the body be about $1.00 \mathrm{mg} \mathrm{RE} /$ day for men, $0.8 \mathrm{mg} /$ day for women and $0.48 \mathrm{mg} / \mathrm{day}$ for children, which corresponds to $12 \mathrm{mg} \beta$-carotene/day for men, $9.6 \mathrm{mg} \beta$-carotene/day for women and $4.8 \mathrm{mg} \beta$-carotene/day for children, respectively, whereas $1 \mu \mathrm{g} \mathrm{RE}$ is equal to $12 \mu \mathrm{g} \beta$-carotene. Respecting the limited extrapolations of results of the present study for the human status, diet added of crude buriti oil supplies almost five times the recommended daily uptake of RE/day for men, six times daily uptake of RE/day for women and 12 times the recommended daily uptake of RE/day for children. On the other hand, refined buriti oil supplies 4.5 times the daily uptake of RE/day for men, almost 6 times the daily uptake of RE/day for women and 11 times the daily uptake of RE/day for children.

The highest vitamin A concentration in plasma was found for the CBO group, confirming the loss of pigments and vitamins often reported for vegetable oils submitted to refinement $[7,10]$. Hepatic vitamin A levels did not differ between groups receiving buriti oil $(p>0.05)$, which were higher than those found for the control group $(p<0.05)$. Plasma retinol is homeostatically controlled, i.e., plasma retinol concentration does not decrease until liver reserves are depleted, which explains the results found [22], suggesting that buriti oil is a major source of dietary vitamin A.

Even though the group that consumed refined buriti oil added to the diet (RBO) ingested lower amounts of $\beta$-carotene, the accumulation of this compound in the liver was the same as the group that ingested greater amount of $\beta$-carotene or that consumed crude buriti oil added to the diet (CBO). The RBO group showed greater efficiency in the conversion of $\beta$-carotene from diet on the body reserves of animals. Comparing the serum and hepatic retinol of RBO group $(54.88 \mu \mathrm{g} / \mathrm{dL}$ and $165.49 \mu \mathrm{g} / \mathrm{g})$ with results obtained by Yuyama et al. [25] (35.21 $\mu \mathrm{g} / \mathrm{dL}$ and $124.15 \mu \mathrm{g} / \mathrm{g})$ for rats fed with lyophilized buriti pulp, it was observed that there was probably a more efficient conversion of $\beta$-carotene from diets containing buriti oil, which resulted in higher plasma and hepatic retinol concentrations.

Although the diet intake was similar among groups $(p>0.05)$, the serum and hepatic $\alpha$-tocopherol concentration was higher in $\mathrm{CBO}$ and $\mathrm{RBO}$ groups, respectively, indicating the presence of this compound in greater amounts in diets added of buriti oil (Figure 2). The use of animal models allows simulating the event investigated in humans, thus, considering the data obtained, it is possible to calculate the efficiency of diet added of buriti oil in relation to guidelines of the Dietary Reference Intakes-DRIs [24] and vitamin contents E for humans. The DRI recommendation for vitamin E for adults is $10 \mathrm{mg} /$ day and for children is on average $8.5 \mathrm{mg} /$ day, and it was observed that the diet consumed by the CBO group $(51.00 \pm 0.82 \mathrm{mg}$ of alpha tocopherol $/ \mathrm{kg}$ ) could correspond to supply almost five times the DRI value for adults and six times the DRI values for children, while the diet consumed by the RBO group ( $46.80 \pm 0.60 \mathrm{mg}$ of alpha tocopherol $/ \mathrm{kg}$ ) could supply almost five times the DRI values for adults and five and a half times the DRI values for children. Therefore, it could be inferred that diet added of crude or refined buriti oil is a source of vitamin $\mathrm{E}$ and is able to supply more than $15 \%$ of DRIs for adults and children. In addition, due to its antioxidant properties, tocopherol provides greater chemical stability to buriti oil, increasing its shelf life and minimizing biochemical oxidation reactions [26], which may contribute to the processing of this oil.

The difference between the amounts of serum tocopherol detected in animals fed with crude buriti oil $(71.6 \pm 1.00 \mu \mathrm{g} / \mathrm{dL})$ compared with those who consumed refined buriti oil $(50.2 \pm 0.90 \mu \mathrm{g} / \mathrm{dL})$ results from the reduction of this compound during the refining process [10]. However, both groups had serum tocopherol contents higher than those found by Dromitrovic et al. [27] in animals fed with olive oil or 
corn oil, $29 \mu \mathrm{g} / \mathrm{dL}$ and $33 \mu \mathrm{g} / \mathrm{dL}$, respectively. The results of the present study also showed higher serum vitamin $E$ concentrations in rats fed with coconut oil $(14.9 \pm 2.26 \mu \mathrm{mol} / \mathrm{mmol})$ or hydrogenated vegetable fat $(8.67 \pm 1.61 \mu \mathrm{mol} / \mathrm{mmol})$ found by Naziroglu and Brandsch [28].

A

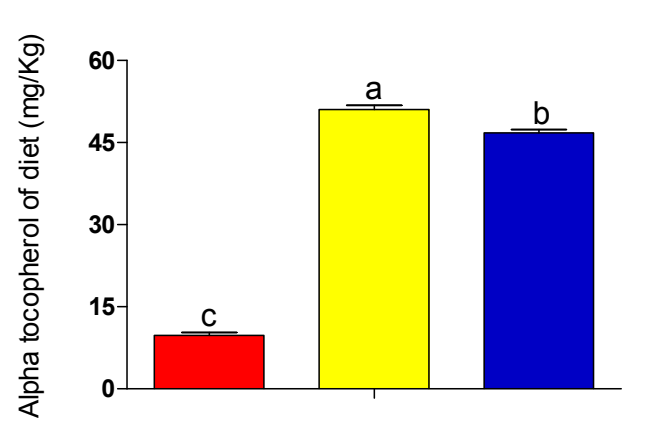

C

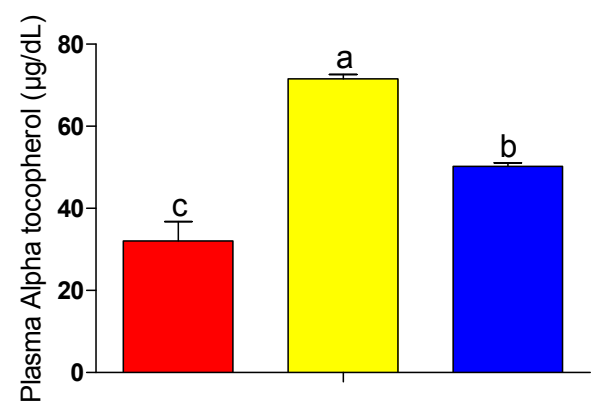

B

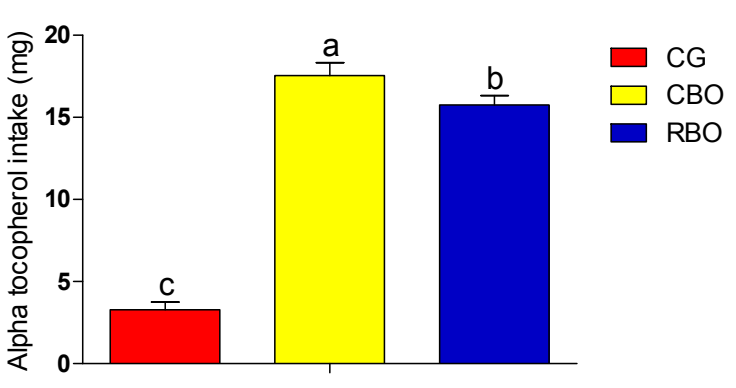

$\mathrm{D}$

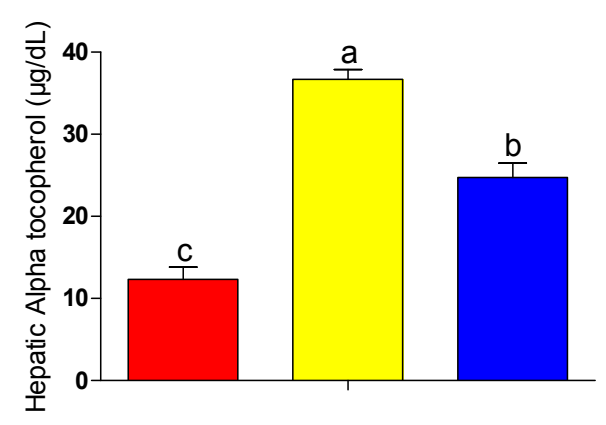

Figure 2. Content and intake of alpha tocopherol of diets and serum and hepatic alpha tocopherol of Wistar rats fed with diets added of soybean oil or refined or crude buriti oil. Panel A: alpha tocopherol of diet; Panel B: alpha tocopherol intake; Panel C: Plasma alpha tocopherol level; Panel D: Hepatic alpha tocopherol level. Means followed by different letters indicate significant difference with error probability $p<0.05$, according to the Tukey test. Abbreviations: Groups: $\mathrm{CG}=$ control group with $\mathrm{AIN}-93 \mathrm{G}$ diet; $\mathrm{CBO}=$ experimental group with AIN-93G diet with crude buriti oil; RBO = Experimental group with AIN-93G diet with refined buriti oil.

The liver $\alpha$-tocopherol concentration in the CBO group $(36.68 \pm 1.19 \mu \mathrm{g} / \mathrm{g})$ was three times higher and that of the RBO group $(24.7 \pm 1.79 \mu \mathrm{g} / \mathrm{g})$, and twice $(p<0.05)$ the $\alpha$-tocopherol concentration found in the liver of animals fed with soybean oil $(12.33 \pm 1.5 \mu \mathrm{g} / \mathrm{g})$, which demonstrates the easy absorption of vitamin $\mathrm{E}$ from buriti oil.

The amount of vitamin $\mathrm{E}$ found in the liver of rats fed with diet added of crude buriti oil (CBO) was higher than that reported for rats consuming canola oil and olive oil, $25 \mu \mathrm{g} / \mathrm{g}$ and $33 \mu \mathrm{g} / \mathrm{g}$ [27]. In addition, $\mathrm{CBO}$ and RBO groups showed liver tocopherol concentrations higher than those found by Naziroglu and Brandsch [28] in the liver of rats that consumed coconut oil $(19.8 \pm 10.3 \mu \mathrm{g} / \mathrm{g})$ and hydrogenated vegetable fat $(19.6 \pm 9.8 \mu \mathrm{g} / \mathrm{g})$.

Studies have reported that the consumption of oils containing high concentration of natural antioxidants such as tocopherol may protect against possible physiological damage such as lipid peroxidation, play a role in the healing process and improve the antioxidant defense system [27,29-32]. 
The diets offered to the animals in this study simulated the daily consumption of soybean oil, crude oil or refined buriti without interference from the consumption of other vegetable oils, in order to evaluate and compare the individual effects of each oil in an animal model. However, it is important to highlight that the amounts of carotenoids and tocopherols present in diets compared with the intake recommendations of these nutrients for humans $[23,24]$ should be evaluated with caution, respecting the experimental design of the study, the substance tested of the dose translated from animal to humans and the time window used to test the hypothesis [32-34]. All these factors must consider the " $R$ " of refinement and the " $R$ " reduction that are essential in animal studies and must respect the limitations in translating the animal model used, not just as a simple conversion of results obtained in animal models to humans [32-34].

\subsection{Lipid and Haematological Profiles}

Regarding data on red blood cells, there was a higher percentage of hematocrit, i.e., greater amount of red blood cells in the group receiving diet added of crude buriti oil when compared to the other groups, but no difference was found in the hemoglobin concentration (Table 3).

Table 3. Lipid and haematological profile of Wistar rats fed with diets added of soybean oil or refined or crude buriti oil.

\begin{tabular}{cccc}
\hline \multirow{2}{*}{ Biochemical Data } & \multicolumn{3}{c}{ Animals Groups } \\
\cline { 2 - 4 } & $\mathbf{C G}(\mathbf{n}=\mathbf{1 0})$ & CBO $(\mathbf{n}=\mathbf{1 0})$ & $\mathbf{R B O}(\mathbf{n}=\mathbf{1 0})$ \\
\hline Hemoglobin $(\mathrm{g} / \mathrm{dL})$ & $10.55 \pm 1.23^{\mathrm{a}}$ & $11.14 \pm 0.45^{\mathrm{a}}$ & $10.9 \pm 0.46^{\mathrm{a}}$ \\
Hematocrit $(\%)$ & $41.38 \pm 8.4^{\mathrm{ab}}$ & $48.25 \pm 3.11^{\mathrm{a}}$ & $35.25 \pm 10.24^{\mathrm{b}}$ \\
TC $(\mathrm{mg} / \mathrm{dL})$ & $96.83 \pm 13.97^{\mathrm{b}}$ & $131.51 \pm 15.52^{\mathrm{a}}$ & $52.25 \pm 6.88^{\mathrm{c}}$ \\
HDL-C (mg/dL) & $24.38 \pm 11.6^{\mathrm{a}}$ & $23.64 \pm 2.04^{\mathrm{a}}$ & $13.41 \pm 1.59^{\mathrm{b}}$ \\
TC/HDL-C (mg/dL) & $3.91 \pm 0.64^{\mathrm{b}}$ & $5.44 \pm 0.46^{\mathrm{a}}$ & $3.96 \pm 0.31^{\mathrm{b}}$ \\
VLDL-C (mg/dL) & $16.18 \pm 6.36^{\mathrm{a}}$ & $19.88 \pm 2.35^{\mathrm{a}}$ & $8.86 \pm 0.86^{\mathrm{b}}$ \\
LDL-C (mg/dL) & $57.88 \pm 3.86^{\mathrm{b}}$ & $87.49 \pm 5.28^{\mathrm{a}}$ & $30.84 \pm 5.24^{\mathrm{c}}$ \\
TAG (mg/dL) & $81.50 \pm 32.33^{\mathrm{a}}$ & $99.38 \pm 11.75^{\mathrm{a}}$ & $44.25 \pm 4.68^{\mathrm{b}}$ \\
AST (IU/L) & $10.75 \pm 1.58^{\mathrm{ab}}$ & $12.75 \pm 1.91^{\mathrm{a}}$ & $10.00 \pm 2.78^{\mathrm{b}}$ \\
ALT (IU/L) & $12.13 \pm 1.81^{\mathrm{a}}$ & $14.38 \pm 2.00^{\mathrm{a}}$ & $11.75 \pm 2.55^{\mathrm{a}}$ \\
\hline
\end{tabular}

Means followed by different letters in the same line indicate a significant difference error probability $p<0.05$, according to the Tukey test. Abbreviations: triacylglycerol (TAG); Serum cholesterol (TC); high density lipoprotein cholesterol (HDL-C); low density lipoprotein cholesterol (LDL-C); VLDL = very low density lipoprotein cholesterol; ALT $=$ alanine aminotransferase; AST $=$ aspartate aminotransferase. Groups: $\mathrm{CG}=$ control group with AIN-93G diet; $\mathrm{CBO}=$ experimental group with AIN-93G diet with crude buriti oil; $\mathrm{RBO}=$ Experimental group with AIN-93G diet with refined buriti oil

The consumption of $\beta$-carotene increases iron absorption in the human body [35], which is in agreement with results found, in which the highest hematocrit percentage was observed in the group that ingested higher vitamin A contents, that is, animals that received crude buriti oil (CBO).

The results observed for HDL-C, LDL-C and TC in the group of animals that received refined buriti oil (RBO) are in agreement with those obtained by Asadi et al. [11] for rats fed with diet containing corn oil (HDL-C $16.75 \mathrm{mg} / \mathrm{dL}$, LDL-C $11.28 \mathrm{mg} / \mathrm{dL}$ and TC $45.03 \mathrm{mg} / \mathrm{dL}$ ), grape seed oil (HDL-C $14.59 \mathrm{mg} / \mathrm{dL}$, 
LDL-C $28.06 \mathrm{mg} / \mathrm{dL}$ and TC $59.60 \mathrm{mg} / \mathrm{dL}$ ) and canola oil (HDL-C $18.26 \mathrm{mg} / \mathrm{dL}$ LDL-C $22.86 \mathrm{mg} / \mathrm{dL}$ and TC $55.81 \mathrm{mg} / \mathrm{dL}$ ). TAG, TC and HDL-C concentrations in groups fed with diet added of crude (CBO) or refined buriti oil (RBO) were lower than those found by Tzang et al. [36] in hamsters fed with crude linseed oil (TAG 100-200 mg / dL, TC $177.59 \mathrm{mg} / \mathrm{dL}$ and HDL-C approx. $70 \mathrm{mg} / \mathrm{dL}$ ). TAG and TC concentrations in group fed with diet added refined buriti oil (RBO) were similar those founds by Quiles et al. [37] in rats fed with diet containing olive oil (TAG $56.7 \mathrm{mg} / \mathrm{dL}, \mathrm{TC} 68.8 \mathrm{mg} / \mathrm{dL}$ ). It is also important to emphasize that despite the consumption of buriti oil have shown beneficial health effects, the consumption of olive oil should be highlighted because it is a non-atherogenic oil among all the oils consumed in the world and present an excellent profile fatty acids, a high content of antioxidants such as polyphenols and fat-soluble vitamins [38,39]. Arbonés-Mainar et al. [40] showed that consumption of a Western diet supplemented with one of several varieties of extra virgin olive oil decreased atherosclerosis lesions, reduced plaque size, and decreased macrophage recruitment in animal model. The effects of olive oil consumption [27,30,37,40] and various other oils such as soybean [28,41], corn, canola $[11,30,42]$, among others $[12,17,36,42]$, have already been evaluated and were well documented in animal models and translating these results to humans $[4,43,44]$, with similar effects among models, respecting the extrapolation of results.

There was a decrease in all serum lipid parameters analyzed of animals fed with diet containing refined oil buriti (RBO) compared to those fed with diet added of crude buriti oil (CBO). This result agrees with results obtained by Berger et al. [17], who compared the blood lipid profile of rats fed with crude and refined amaranth oil. However, higher total cholesterol values were observed for group receiving diet added of crude buriti oil (CBO). This result suggests that although crude oils have higher concentration of phytosterols, vitamins, antioxidants and pigments [6], which are associated with reduced serum cholesterol and oxidative stress, crude oils also have higher concentration of oxidized substances and impurities such as peroxides, hydroperoxides, volatile (aldehydes, ketones) and nonvolatile compounds (carbonyls and cyclic fatty acids), which have been associated with dyslipidemia, hypertension, inflammation, oxidative stress, endothelial dysfunction and atherosclerosis $[45,46]$.

The refining process removes oxidized substances; thus, even if the process causes loss of approximately $13.08 \%$ of $\beta$-carotene and $12.46 \%$ of tocopherol (compared to the crude buriti oil), the removal of the oxidized substances might be related to the greater effectiveness of refined Buriti oil in lowering LDL-C and total cholesterol levels in rats from the RBO group. Probably, although carotenoids and tocopherols were reduced during the refining process, the quantities of antioxidants present in refined buriti oil were effective to minimize lipoprotein oxidation and consequently reduce the plasma levels of animals (RBO) [47,48].

The consumption of refined buriti oil reduces the concentration of triglycerides, total cholesterol and fractions (HDL-C, LDL-C and VLDL-C) in healthy rats. These results are relevant but should be carefully assessed with regard to the consumption of refined buriti oil associated with the prevention and treatment of cardiovascular diseases and dyslipidemias, considering that the animal model used in this study did not perform the experiment with dyslipidemia-induced rats.

Serum aminotransferase levels (ALT and AST) are reliable indicators of functional or structural alteration of liver cell [49]. In the present study, the ALT values obtained ranged from 11.75 to 14.38 IU and AST values from 10.00 to $12.75 \mathrm{IU}$, which are lower than those observed by Ohara et al. [42] in rats fed with diets added of rapeseed oil (18.1 IU ALT and 59.8 IU AST). The CBO group showed the highest 
AST value; however, the ALT concentration showed no difference among groups $(p<0.05)$. According to Sugiura et al. [50], there is an inverse association of serum retinol concentrations with serum AST and ALT, which was not observed in this study. However, according to Yeh et al. [46], ALT and AST aminotransferases can increase with increasing consumption of oxidized oil, suggesting that the higher AST values found in CBO group may be related to the presence of oxidation products, which would be removed during the refining process of oils.

\section{Experimental Section}

\subsection{Oil Samples}

The oils used in this study were all obtained from six different batches mixed to form the test sample. Buriti oil samples were obtained and characterized as Aquino et al. [7]. The buriti oil was extracted by hand from ripe fruit by cooking in water for $20 \mathrm{~min}$ at temperature of $\pm 60^{\circ} \mathrm{C}$ and the oil was separated from the aqueous fraction. Subsequently, crude oil was used in the refining process, followed by degumming, neutralization, washing and drying steps [7]. The refined soybean oil (Soya ${ }^{\circledR}$, São Paulo, Brazil) was purchased in supermarket of João Pessoa, Brazil, was used as control and characterized according previously described procedures AOAC [51]. The composition of soybean oil (control), as well as crude and refined buriti oil was analyzed in triplicate (Table 4).

Table 4. Fatty acids, $\beta$-carotene and tocopherol present in soybean oil, crude and refined buriti oils.

\begin{tabular}{|c|c|c|c|}
\hline \multirow{2}{*}{ Composition } & \multicolumn{3}{|c|}{ Vegetable Oils } \\
\hline & Soybean Oil * & Crude Buriti Oil & Refined Buriti Oil \\
\hline$\beta$-Carotene $\left(\mathrm{mg} \cdot \mathrm{kg}^{-1}\right)$ & $420.02 \pm 2.80^{c}$ & $911.40 \pm 2.40^{\mathrm{a}}$ & $792.10 \pm 4.54^{\mathrm{b} * *}$ \\
\hline Tocopherol $\left(\mathrm{mg} \cdot \mathrm{kg}^{-1}\right)$ & $305.20 \pm 2.10^{\mathrm{c}}$ & $810.00 \pm 2.70^{a}$ & $709.00 \pm 2.40^{\mathrm{b} * * *}$ \\
\hline \multicolumn{4}{|c|}{ Fatty Acids (\%) } \\
\hline Miristic acid-C 14:0 & $17.10 \pm 0.02^{\mathrm{a}}$ & $0.50 \pm 0.04^{b}$ & $0.50 \pm 0.02^{\mathrm{c}}$ \\
\hline Margaric acid-C 17:0 & $11.20 \pm 0.03^{b}$ & $0.30 \pm 0.02^{\mathrm{a}}$ & $0.20 \pm 0.01^{\mathrm{c}}$ \\
\hline Stearic acid-C18:0 & $3.40 \pm 0.03^{\mathrm{a}}$ & $2.30 \pm 0.02^{b}$ & $3.90 \pm 0.01^{\mathrm{c}}$ \\
\hline $\begin{array}{c}\text { Total saturated fatty } \\
\text { acids-SFA\% }\end{array}$ & $31.70 \pm 0.088^{\mathrm{a}}$ & $3.10 \pm 0.08^{c}$ & $4.6 \pm 0.04^{a}$ \\
\hline Palmitoleic acid-C16:1 & n.d. $* * * *$ & $19.60 \pm 0.02$ & $19.40 \pm 0.01$ \\
\hline Oleic acid-C18:1 & $23.60 \pm 0,04^{\mathrm{b}}$ & $72.70 \pm 0.02^{\mathrm{a}}$ & $72.20 \pm 0.02^{\mathrm{c}}$ \\
\hline $\begin{array}{l}\text { Total monounsaturated } \\
\text { fatty acids-MUFA\% }\end{array}$ & $23.60 \pm 0.04^{b}$ & $92.30 \pm 0.04^{\mathrm{a}}$ & $91.60 \pm 0.03^{c}$ \\
\hline Linoleic acid-C 18:2 & $39.90 \pm 0.02^{\mathrm{a}}$ & $2.60 \pm 0.04^{b}$ & $2.30 \pm 0.01^{\mathrm{c}}$ \\
\hline Linolenic acid-C 18:3 & $4.80 \pm 0.02^{\mathrm{a}}$ & $2.00 \pm 0.01^{\mathrm{b}}$ & $1.50 \pm 0.01^{\mathrm{c}}$ \\
\hline $\begin{array}{l}\text { Total polyunsaturated } \\
\text { fatty acids-PUFA\% }\end{array}$ & $44.70 \pm 0.04^{\mathrm{a}}$ & $4.60 \pm 0.05^{b}$ & $3.80 \pm 0.01^{c}$ \\
\hline
\end{tabular}

Means followed by different letters in the same line indicate significant difference error probability $p<0.05$, according to the Tukey test. * Control oil; ** Loss of $\beta$-carotene after refining $=13.08 \%$; *** Tocopherol loss after refining $=12.46 \% ; * * * *$ n.d. $=$ not detected. 


\subsection{Animals and Diet}

The experimental protocol was approved by the Ethics Committee for Animal Research - CEPA — UFPE under number 23076.015472/2009-25 and followed the guidelines of the Brazilian College for Animal Experimentation-COBEA. Thirty just-weaned male Wistar rats aged \pm 21 days coming from the Animal facilities of the Department of Nutrition, Federal University of Pernambuco (UFPE) were used. The animals were randomized into three groups, each with 10 animals and kept in individual cages with ad libitum water and diet, temperature of $22 \pm 1{ }^{\circ} \mathrm{C}$, relative humidity between $50 \%$ and $55 \%$, and dark/light cycle of $12 \mathrm{~h}$.

The levels of macro and micronutrients in diets were calculated and balanced following recommendations of the American Institute of Nutrition (AIN) [52]. The level of oils (soybean, refined or crude buriti oils) added in diets was defined as $7 \mathrm{~g}$ oil/100 $\mathrm{g}$ diet for growing rodents (AIN-93 G), in accordance with the rules of American Institute of Nutrition (AIN) [52]. Considering the results observed in preliminary assays and results already published $[19,20]$ about the influence of oil consumption on the lipid biochemical and metabolism of fat-soluble vitamins, the diets containing soybean, refined or crude buriti oils were administered for 28 days from weaning. The control group (CG) received diet containing soybean oil as lipid source; one experimental group received diet containing crude buriti oil (CBO) as lipid source and the other experimental group received diet containing refined buriti oil (BRO) as lipid source (Table 5).

Table 5. Composition of diets of control group added of soybean oil (CG) and experimental groups added of crude (CBO) or refined buriti oil (RBO).

\begin{tabular}{|c|c|c|c|c|}
\hline \multirow{2}{*}{ Ingredients * } & \multirow{2}{*}{$\begin{array}{c}\text { Amounts } \\
(\mathrm{g} / 100 \mathrm{~g})\end{array}$} & CS & CBO & RBO \\
\hline & & Energy (Kcal) & Energy(Kcal) & Energy(Kcal) \\
\hline Corn starch & 52.9 & 186.10 & 186.10 & 186.10 \\
\hline Casein & 20.0 & 68.00 & 68.0 & 68.0 \\
\hline Sucrose & 10.0 & 40.00 & 40.00 & 40.0 \\
\hline Fiber & 5.0 & - & - & - \\
\hline Soybean oil or buriti oil & 7.0 & 63.0 & 63.0 & 63.0 \\
\hline Mix of minerals & 3.5 & - & - & - \\
\hline Mix of vitamins & 1.0 & - & - & - \\
\hline D.L-Methionine & 0.3 & - & - & - \\
\hline Choline Bitartrate & 0.3 & - & - & - \\
\hline Total & 100 & 357.10 & 357.10 & 357.10 \\
\hline
\end{tabular}

* AIN-93G diet [52].

On the basic diet of all groups, a mix of vitamins containing 4,000 IU of vitamin A (2.4 mg of $\beta$-carotene) and $75 \mathrm{IU}$ of vitamin $\mathrm{E}(49.95 \mathrm{mg}$ of $\alpha$-tocopherol) were added to each $\mathrm{kg}$ of diet, as recommended by the American Institute of Nutrition (AIN) [18]. Weight of animals and diet consumption were weekly measured throughout the 28 days of the experimental period to determine the feed efficiency coefficient according to protocol proposed by Campbell [53]. 


\subsection{Murine Anthropometric Parameters}

Murine parameters were obtained from anesthetized animals prior to euthanasia, and using a measuring tape, the following were measured: abdominal circumference $(\mathrm{AC})$ immediately prior to the hind leg and chest circumference (CC), immediately behind the front leg, plus body weight and body length, measured from nose to base of tail. The Body Mass Index (BMI) was calculated by dividing body weight ( $\mathrm{g}$ ) by the squared length $\left(\mathrm{cm}^{2}\right)$ and the Lee index (LI) was calculated by the cube root of body weight $(\mathrm{g})$ divided by length $(\mathrm{cm})[19]$.

After 28 days of experiment and after $12 \mathrm{~h}$ fasting, the animals were anesthetized with $1 \mathrm{~mL}$ ketamine hydrochloride and $1 \mathrm{ml}$ xylazine hydrochloride per $\mathrm{kg}$ body weight. Heparin (500 IU/kg body weight) was intraperitoneally administrated as anticoagulant and the animals were perfused through the left ventricle (cardiac puncture) and the serum was used in biochemical analyses. The liver was removed for determination of vitamins $\mathrm{A}$ and $\mathrm{E}$, washed with $\mathrm{NaCl}$ solution $(0.9 \mathrm{~g} / 100 \mathrm{~mL})$, dried on absorbent paper and frozen until moment of analyses.

\subsection{Determination of Vitamins A and E in Diets and Intake of $\beta$-Carotene and Alpha Tocopherol by Rats}

Vitamins A and E were determined according to Prado et al. [54]. Briefly, each sample (5 g) was macerated and extracted with ethanol $(10 \mathrm{~mL})$ containing $0.25 \%$ butylated hydroxytoluene (BHT), distilled water $(5 \mathrm{~mL})$, and sodium chloride $(0.5 \mathrm{~g})$. Subsequently, hexane $(10 \mathrm{~mL})$ were added and the material was stirred and submitted to ultrasonic bath for $3 \mathrm{~min}$ for homogenization. After centrifugation $\left(185 \times \mathrm{g} / 3 \mathrm{~min} / 10^{\circ} \mathrm{C}\right)$, the hexane extract was collected in amber glass. The procedure was performed five times. The hexane fraction was evaporated using nitrogen gas and after the removal of hexane, fractions were resuspended with $3.0 \mathrm{~mL}$ methanol and filtered through a $0.5-\mu \mathrm{m}$ Millipore Fluoropore membrane. Filtered extract samples were injected into a High Performance Liquid Chromatography (HPLC) system (model 2699, Varian, Harbor City, CA, USA) coupled to a diode array detector (DAD) and a C18 chromatography column (Inertisil, $150 \times 4.6 \mathrm{~mm} 5 \mu \mathrm{m}$, Chrompack-Varian, Middelburg, The Netherlands). Elution was performed with methanol: water $(98: 2)$ at flow rate of $1.0 \mathrm{~mL} \cdot \mathrm{min}^{-1}$. The injection volume was $20 \mu \mathrm{L}$, and detection wavelength of $325 \mathrm{~nm}$. Sample identification was confirmed by comparing retention times to standard compounds under the same chromatographic conditions. Quantitation was accomplished by internal calibration using $\beta$-carotene (C-9750, Sigma, St. Louis, MO, USA) and $\alpha$-tocopherol (T-3251, Sigma) standards. The intake of vitamin A as $\beta$-carotene and vitamin $\mathrm{E}$ as $\alpha$-tocopherol were calculated as the amount of $\beta$-carotene and $\alpha$-tocopherol, respectively, determined in the three types of diet based on of the amount of diet consumed by each group of animals.

\subsection{Determination of Serum and Hepatic Retinol and Alpha Tocopherol}

Hepatic and serum retinol and $\alpha$-tocopherol concentrations were determined by HPLC (model Ultimate 3000, Dionex, São Paulo, Brazil), using a $\mathrm{C}_{18}$ column measuring $4.6 \times 2.50 \mathrm{~mm} \times 5 \mu \mathrm{m}$, pre-column, detector set at $325 \mathrm{~nm}$ with methanol as mobile phase, flow rate of $1.5 \mathrm{~mL} \cdot \mathrm{min}^{-1}$ and peak holding at 3.6 minutes. For quantification of serum retinol and alpha tocopherol, $2 \mathrm{ml}$ of blood were centrifuged $\left(1665 \times \mathrm{g} / 10 \mathrm{~min} / 10^{\circ} \mathrm{C}\right)$ to remove the serum. Subsequently, $100 \mu \mathrm{L}$ of sample was added 
to $100 \mu \mathrm{L}$ of ethanol to precipitate proteins with stirring for 10 seconds. Then, $200 \mu \mathrm{L}$ of hexane were added and stirred for 45 seconds and the material was centrifuged $\left(1665 \times \mathrm{g} / 5 \mathrm{~min} / 10^{\circ} \mathrm{C}\right)$. Following this procedure, $100 \mu \mathrm{L}$ of the supernatant were collected and submitted to evaporation with nitrogen [55]. The samples were dissolved again with $100 \mu \mathrm{L}$ of methanol, from which $20 \mu \mathrm{L}$ were taken to carry out chromatographic analyses.

Hepatic retinol was quantified according to procedure adapted from Stahl et al. [56]. A total of $1 \mathrm{~g}$ of liver was added to ethanol $(2 \mathrm{~mL})$ and homogenized for 2 min using mechanical stirrer and then in vortex for another $2 \mathrm{~min}$ with the addition of hexane $(2 \mathrm{~mL})$. Subsequently, the material was centrifuged $\left(18,501 \times \mathrm{g} / 10 \mathrm{~min} / 10{ }^{\circ} \mathrm{C}\right)$, with drying of the supernatant under nitrogen atmosphere and resuspended in methanol $(100 \mu \mathrm{L})$, from which $20 \mu \mathrm{L}$ were taken to carry out chromatographic analyses. Quantitation was accomplished by internal calibration using retinol (R-7632, Sigma) and $\alpha$-tocopherol (T-3251, Sigma) standards.

\subsection{Lipid and Haematological Profiles}

Blood was collected from anesthetized animal by direct cardiac puncture $(4 \mathrm{~mL})$ and centrifuged $\left(807 \times \mathrm{g} / 10 \mathrm{~min} / 20^{\circ} \mathrm{C}\right)$. Serum was kept at room temperature (25) for determination of cholesterol (enzyme) HDL-C (polyethylene glycol-PEG), LDL-C (polyethylene glycol-PEG), VLDL-C (polyethylene glycol-PEG) and triglyceride (enzymatic) using Dolles (Goiânia, GO, Brasil) kits according to manufacturer's instructions, as well as measurements of hematocrit and hemoglobin, aspartate transaminase (AST) and alanine transaminase (ALT).

\subsection{Statistical Analyses}

Randomized design was used and the analysis of results was performed using SPSS for Windows Evaluation Edition-14.0 (SPSS. Inc., Chicago, IL, USA) [57], considering the error probability (p) less than or equal $(\leq)$ to $5 \%$. In order to meet the methodological assumptions of parametric tests and obtain consistent results, the sample homogeneity test was applied. The values obtained from three or more independent variables were submitted to analysis of variance (ANOVA) using the F test; however, for those with no homogeneity among samples, the Welch test for robustness was used, and for those showing significance, the Tukey's test for multiple comparisons was applied.

\section{Conclusions}

The results obtained demonstrate for the first time the metabolic efficiency of crude or refined buriti oil used in the diet as a source of fatty acids and the antioxidant vitamins A and E. However, the consumption of refined buriti oil allows better feed conversion and improves the lipid profile by reducing LDL-cholesterol, triglycerides (TAG) and aspartate transaminase (AST), without changing the murine parameters of healthy rats.

\section{Acknowledgments}

The authors would like to thank the Center for Micronutrient Research-CIMICRON Department of Nutrition, Federal University of Paraíba-UFPB, Laboratory of analysis of vitamins. 


\section{Author Contributions}

JSA — study design, implementation of experimental part and data collection, and analysis and interpretation of data. JKBS — study design and interpretation of data. MM and TCMS — drafting the manuscript, critical revision of the content and interpretation of data. RJM and RLT - analysis and interpretation of data. TLMS - study design, drafting of the manuscript and critical revision of the content. All authors contributed to and have approved the final manuscript.

\section{Abbreviations}

AC-Abdominal circumference

AIN-American Institute of Nutrition

ALT-Alanine transaminase

AST-Aspartate transaminase

BMI—Body Mass Index

BHT-Butylated Hydroxytoluene

CBO - Experimental group that consumed diet added of casein and crude buriti oil CG-Control group that consumed diet added of casein and soybean oil

$\mathrm{CC}$ - Chest circumference

CEPA-Ethics Committee on Animal Research

COBEA-Brazilian College of Animal Experimentation

DAD_Diode Array Detector

DRIs-Dietary Reference Intakes

FEC-Feed Efficiency Coefficient

HDL-C - High density lipoprotein

HPLC_-High Performance Liquid Chromatography

IU-International Unit (vitamins)

LI-Lee index

LDL-C - Low density lipoprotein

$\mathrm{RBO}$ - Experimental group that consumed diet containing casein and refined buriti oil

RE-Retinol equivalents

TAG-triglycerides

UFPE - Federal University of Pernambuco

VLDL-C-Very low density lipoprotein

\section{Conflicts of Interest}

The authors declare that there are no conflicts of interest. 


\section{References}

1. Wawrzyniaka, A.; Górnicka, M.; Hamułka, J.; Gajewska, M.; Drywieńa, M.; Pierzynowska, J.; Gronowska-Senger, A. $\alpha$-Tocopherol, ascorbic acid, and $\beta$-carotene protect against oxidative stress but reveal no direct influence on p53 expression in rats subjected to stress. Nutr. Res. 2013, 33, 868-875.

2. Takahashi, K.; Komaru, T.; Takeda, S.; Takeda, M.; Koshida, R.; Nakayama, M.; Kokusho, Y.; Kawakami, Y.; Yamaguchi, N.; Miyazawa,T.; et al. Gamma-tocopherol, but not $\alpha$-tocopherol, potently inhibits neointimal formation induced by vascular injury in insulin resistant rats. $J$. Mol. Cell. Cardiol. 2006, 41, 544-554.

3. Canas, J.A.; Damaso, L.; Altomare, A.; Killen, K.; Hossain, J.; Balagopal, B.P. Insulin resistance and adiposity in relation to serum $\beta$-carotene levels. J. Pediatr. 2012, 161, 58-64.

4. López-Miranda, J.; Pérez-Jiménez, F.; Ros, E.; De Caterina, R.; Badimón, L.; Covas, M.I.; Escrich, E.; Ordovás, J.M.; Sorique, F.; Abiá, R.; et al. Olive oil and health: Summary of the II international conference on olive oil and health consensus report, Jaén and Córdoba (Spain) 2008. Nutr. Metab. Cardiovasc. Dis. 2010, 20, 284-294.

5. Widmer, R.J.; Flammer, A.J.; Lermanl, O.; Lerman, A. The Mediterranean diet, its components and cardiovascular disease. Am. J. Med. 2015, 128, 229-238.

6. Gunstone, F.D. Vegetable Oils in Food Technology: Composition, Properties and Uses; Blackwell Publishing: Oxford, UK, 2002.

7. Aquino, J.S.; Pontes Pessoa, D.C.N.; Araújo, K.L.G.V.; Epaminondas, P.S.; Schuler, A.R.P.; Souza, A.G.; Stamford, T.L.M. Refining of Buriti oil (Mauritia flexuosa) originated from the Brazilian Cerrado: Physicochemical, thermal-oxidative and nutritional implications. J. Braz. Chem. Soc. 2012, 23, 2012-2019.

8. Szydłowska-Czerniaka, A.; Trokowski, K.; Karlovits, G.; Szłyk, E. Effect of refining processes on antioxidant capacity, total contents of phenolics and carotenoids in palm oils. Food Chem. 2011, 129, 1187-1192.

9. Landucci, G.; Pannocchia, G.; Pelagagge, L.; Nicolella, C. Analysis and simulation of an industrial vegetable oil refining process. J. Food Eng. 2013, 116, 840-851.

10. Oterhals, A.; Vogt, G. Impact of Extraction, Refining and Concentration Stages on the Stability of Fish Oil. Food Enrichment with Omega-3 Fatty Acids; Woodhead Publishing: Cambridge, UK, 2013.

11. Asadi, F.; Shahriari, A.; Chahardah-Cheric, M. Effect of long-term optional ingestion of canola oil, grape seed oil, corn oil and yogurt butter on serum, muscle and liver cholesterol status in rats. Food Chem. Toxicol. 2010, 48, 2454-2457.

12. Xiao,Y.; Qianchun, D.; Jiqu, X.; Fenghong, H.; Qingde, H.; Zhihua, Y.; Jine, Y. Effects of cold-pressed and vitamin E-enriched flaxseed oils on lipid profile and antioxidant status in high-fat fed rats. Eur. J. Lipid Sci. Technol. 2012, 114, 461-468.

13. Dhavamani, S.; Rao, Y.P.C.; Lokesh, B.R. Total antioxidant activity of selected vegetable oils and their influence on total antioxidant values in vivo: A photochemiluminescence based analysis. Food Chem. 2014, 164, 551-555.

14. Ribeiro, B.D.; Coelho, M.A.Z.; Barreto, D.W. Production of concentrated beta-carotene from buriti (Mauritia vinifera) oil by enzymatic hydrolysis. Food Bioprod. Process 2012, 90, 141-147. 
15. Ribeiro, B.D.; Nascimento, R.F.; Barreto, D.W.; Coelho, M.A.S.; Freitas, S.P. An ethanol-based process to simultaneously extract and fractionate carotenoids from Mauritia flexuosa pulp. Rev. Bras. Frutic. 2010, 32, 657-663.

16. Albuquerque, M.L.S.; Guedes, I.; Alcantara Junior, P. Moreira, S.G.C.; Barbosa Neto, N.M.; Correa, D.S.; Zilio, S.C. Characterization of Buriti (Mauritia flexuosa L.) Oil by Absorption and Emission Spectroscopies. J. Braz. Chem. Soc. 2005, 16, 1113-1117.

17. Berger, A.; Monnard I.; Dionisi, F.; Gumy, D.; Hayes, KC.; Lambelet, P. Cholesterol-lowering properties of amaranth flakes, crude and refined oils in hamsters. Food Chem. 2003, 81, 119-124.

18. Hama, S.; Yoshida, A.; Tamadani, N.; Noda, H.A.; Kondo, A. Enzymatic production of biodiesel from waste cooking oil in a packed-bed reactor: An engineering approach to separation of hydrophilic impurities. Bioresour. Technol. 2013, 135, 417-421.

19. Novelli, L.B.; Diniz, Y.S.; Galhardi, C.M.; Ebaid, G.M.X.; Rodrigues, H.G.; Mani, F.; Fernandes, A.A.; Cicogna, A.C.; Novelli Filho, J.L.V.B. Anthropometrical parameters and markers of obesity in rats. Lab. Anim. 2007, 41, 111-119.

20. Santillán, M.E.; Vincenti, L.M.; Martini, A.C.; de Cuneo, M.F.; Ruiz, R.D.; Mangeaud, A.; Stutz, G. Developmental and neurobehavioral effects of perinatal exposure to diets with different $\omega-6: \omega-3$ ratios in mice. Nutrition 2010, 26, 423-431.

21. Ramos, M.I.L.; Siqueira, E.M.; Isomura, C.C.; Barbosa, A.M.; Arruda S.F. Bocaiuva (Acrocomia aculeata (Jacq) Lodd) improved vitamin A status in rats. J. Agric. Food Chem. 2007, 22, 3186-3190.

22. Siqueira, E.M.A.; Arruda, S.F.; Vargas, R.M.; Souza, E.M.T. $\beta$-Carotene from cassava (Manihot esculenta Crantz) leaves improves vitamin A status in rats. Comp. Biochem. Physiol. C Toxicol. Pharmacol. 2007, 146, 235-240.

23. FAO/WHO. Human Vitamin and Mineral Requirements. In Proceedings of the 7th Joint FAO/OMS Expert Consultation, Bangkok, Thailand, 30 September 2001; p. 286.

24. Institute of Medicine, Food and Nutrition Board. Dietary Reference Intakes for Vitamins C, E, Selenium and Carotenoids; National Academy Press: Washington, WA, USA, 1998.

25. Yuyama, L.K.O.; Yonekura, L.; Aguiar, J.P.L.; Sousa, R.F.S. Biodisponibilidade dos carotenoides do Buriti (Mauritia flexuosa L.) em ratos. Acta Amaz. 1998, 28, 409-415.

26. Rossi, M.; Alamprese, C.; Ratti, S. Tocopherols and tocotrienols as free radical-scavengers in refined vegetable oils and their stability during deep-fat frying. Food Chem. 2007, 102, 812-817.

27. Domitrovic, R.; Tota, M.; Milin, C. Differential effect of high dietary iron on $\alpha$-tocopherol and retinol levels in the liver and serum of mice fed olive oil- and corn oil-enriched diets. Nutr. Res. 2008, 28, 263-269.

28. Naziroglu, M.; Brandsch, C. Dietary hydrogenated soybean oil affects lipid and vitamin E metabolism in rats. J. Nutr. Sci. Vitaminol. 2006, 52, 83-88.

29. Luostarinen, R.L.; Laasonen, K.; Calder, P.C. $\alpha$-Tocopherol concentrations, lipid peroxidation and superoxide dismutase and glutathione peroxidase activities in rat heart and liver after feeding stabilized and unstabilized fish oil. Nutr. Res. 2001, 21, 1529-1544.

30. Odabasoglu, F.; Halici, Z.; Cakir, A.; Halici, M.; Aygun, H.; Suleyman, H.; Cadirci, E.; Atalay, F. Beneficial effects of vegetable oils (corn, olive and sunflower oils) and tocopherol on anti-inflammatory and gastrointestinal profiles of indomethacin in rats. Eur. J. Pharmacol. 2008, $591,300-306$. 
31. Fiedor, J.; Burda, K. Potential Role of Carotenoids as Antioxidants in Human Health and Disease. Nutrients 2014, 6, 466-488.

32. Reagan-Shaw, S.; Nihal, M.; Ahmad, N. Dose translation from animal to human studies revisited. FASEB J. 2008, 22, 659-661.

33. Denayer, T.; Stöhr, T.; van Roy, M. Animal models in translational medicine: Validation and prediction. New Horiz. Transl. Med. 2014, 2, 5-11.

34. Groenink, L.; Folkerts, G.; Schuurman, H.J. European Journal of Pharmacology, Special issue on translational value of animal models: Introduction. Eur. J. Pharmacol. 2015, 759, 1-2.

35. García-Casal, M.N. Carotenoids increase iron absorption from cereal-based food in the human. Nutr. Res. 2006, 26, 340-344.

36. Tzang, B.-S.; Yang, S.-F.; Fu, S.-G.; Yang, H.-C.; Sun, H.-L.; Chen, Y.-C. Effects of dietary flaxseed oil on cholesterol metabolism of hamsters. Food Chem. 2009, 114, 1450-1455.

37. Quiles, J.L.; Ocho, J.J.; Ramirez-Torotsa, C.; Bttino, M.; Huertas, J.R.; Martín, Y.; Mataix, J. Dietary fat type (virgin olive $v s$. sunflower oils) affects age-related changes in DNA double-strand-breaks, antioxidant capacity and blood lipids in rats. Exp. Geront. 2004, 39, 1189-1198.

38. Jacomelli, M.; Pitozzi, V.; Zaid, M.; Larrosa, M.; Toninib, G.; Martini, A.; Urbani, S.; Taticchi, A.; Servili, M.; Dolara, P.; et al. Dietary extra-virgin olive oil rich in phenolic antioxidants and the aging process: Long-term effects in the rat. J. Nutr. Biochem. 2010, 21, 290-296.

39. Condelli, N.; Caruso, M.C.; Galgano, F.; Russo, D.; Milella, L.; Favati, F. Prediction of the antioxidant activity of extra virgin olive oils produced in the Mediterranean area. Food Chem. 2015, 177, 233-239.

40. Arbonés-Mainar, J.M.; Navarro, M.A.; Carnicer, R.; Guillén, N.; Surra, J.C.; Acín S.; Guzmán, M.A.; Sarría, A.J.; Arnal C.; Aguilera, M.P.; et al. Accelerated atherosclerosis in apolipoprotein E-deficient mice fed Western diets containing palm oil compared with extra virgin olive oils: A role for small, dense high-density lipoproteins. Atherosclerosis 2007, 194, 372-382.

41. Kawabata, T.; Shimoda, K.; Horiguchi, S.; Domon, M.; Hagiwara, C.;Takiyama, M.; Kagawa, Y. Influences of stearidonic acid-enriched soybean oil on the blood and organ biochemical parameters in rats. Prostaglandins Leukot. Essent. Fatty Acids 2013, 88, 179-184.

42. Ohara, N.; Naito, Y.; Kasama, K.; Shindo, T.; Yoshida, H.; Nagata, T.; Okuyama, H. Similar changes in clinical and pathological parameters in Wistar Kyoto rats after a 13-week dietary intake of canola oil or a fatty acid composition-based interesterified canola oil mimic. Food Chem. Toxicol. 2009, 47, 157-162.

43. Rueda-Clausen, C.F.; Silva, F.A.; Lindarte, M.A.; Villa-Roel, C.; Gomez, E.; Guitierrez, R.; Cure-Cure, C.; López-Jaramillo, P. Olive, soybean and palm oils intake have a similar acute detrimental effect over the endothelial function in healthy young subjects. Nutr. Metab. Cardiovas. 2007, 1, 50-57.

44. Maki, K.C.; Lawlwss, A.L.; Kelley, K.M.; Kaden, V.N.; Geiger, C.J.; Dicklin, M.R. Corn oil improves the plasma lipoprotein lipid profile compared with extra-virgin olive oil consumption in men and women with elevated cholesterol: Results from a randomized controlled feeding trial. J. Clin. Lipidol. 2015, 9, 49-57.

45. Ng, C.-Y.; Leong, X.-F.; Namasbah, N., Adam, S.K.; Kamisah, Y.; Jaarin, K. Heated vegetable oils and cardiovascular disease risk factors. Vascul. Pharmacol. 2014, 61, 1-9. 
46. Yeh, Y.-H.; Lee, Y.-T.; Hsieh, H.S.; Hwang, D.-F. Effect of red yeast rice on toxicity of oxidized cholesterol and oxidized fish oil in rats. Eur. J. Clin. Nutr. Metab. 2010, 5, 230-237.

47. Sulli, K.C.; Sun, J.; Giraud, D.W.; Moxley, R.A.; Driskell, J.A. Effects of $\beta$-carotene and $\alpha$-tocopherol on the levels of tissue cholesterol and triglyceride in hypercholesterolemic rabbits. J. Nutr. Biochem. 1998, 9, 344-350.

48. Kaulmann, A.; Bohn, T. Carotenoids, inflammation, and oxidative stress-Implications of cellular signaling pathways and relation to chronic disease prevention. Nutr. Res. 2014, 34, 907-929.

49. Plaa, G.L. Evaluation of hepatotoxicity: Physiological and biochemical measures of hepatic function in animals. Comprehensive Toxicol. 2010, 9, 129-140.

50. Sugiura, M.; Nakamura, M.; Ikoma, Y.; Yano, M.; Ogawa, K.; Matsumoto, K.; Kato, M.; Ohshima, M.; Nagao, A. Serum carotenoid concentrations are inversely associated with serum aminotransferases in hyperglycemic subjects. Diabetes Res. Clin. Pract. 2006, 71, 82-91.

51. Association Official Analytical Chemistis. Official Methods of Analysis of the Association Chemistis, 17th ed.; Association Official Analytical Chemistis: Washington, WA, USA, 2002; pp. 10-12.

52. Reeves, P.G.; Nielsen, F.H.; Fahey, G.C. AIN-93: Purified diets for laboratory rodents: final report of the American Institute of Nutrition and hoe writing comitee on the reformulation of the American Institute of Nutrition (AIN)-76A rodent diet. J. Nutr. 1993, 123, 1939-1951.

53. Campbell, J.A. Method for determination of PER and NPR. In Food and Nutrition Board. Evaluation of Protein Quality; Committee on Protein Quality: Washington, WA, USA, 1963; pp. 31-32.

54. Prado, J.P.S.; Cavalheiro, J.M.O.; Silva, F.V.G.; Queiroga Neto, V.; Bora, P.S.; Cavalheiro, T.B. Thermal stability of vitamins $\mathrm{A}$ and $\mathrm{E}$ in rations and vitamin premixes for shrimp. Cien. Rural 2011, $41,544-549$.

55. Furr, H.C; Tranuminardjo, S.A.; Olson, J.A. Training Manual for Assessing Vitamin a Status by Use of the Modified Relative Dose Response and the Relative Dose Response Assays; Office of Nutrition Bureau for Research and Development: Washington, WA, USA, 1992.

56. Stahl, W; Sies, H. Antioxidant activity of carotenoids. Mol. Asp. Med. 2003, 24, 345-351.

57. SPSS for Windows Evaluation Version 14.0 [Computer program]; LEAD Technologies SPSS Inc.: Chicago, IL, USA, 2005.

Sample Availability: Not available.

(C) 2015 by the authors; licensee MDPI, Basel, Switzerland. This article is an open access article distributed under the terms and conditions of the Creative Commons Attribution license (http://creativecommons.org/licenses/by/4.0/). 